\title{
Quality control practices, service quality and customers' satisfaction: The case of non-audit services provided by SMPs to SMEs in Malaysia
}

\author{
Datin Hasnah Haron ${ }^{1 \star}$, Sofri Yahya ${ }^{1}$, Yuvaraj a/I Ganesan ${ }^{1}$, Dato’ Ishak Ismail ${ }^{2}$, Lok Char Lee ${ }^{2}$ \\ and Dato' Daing Nasir Ibrahim ${ }^{3}$ \\ ${ }^{1}$ Graduate School of Business, University Sains Malaysia, Penang, Malaysia. \\ ${ }^{2}$ School of Management, University Sains Malaysia, Penang, Malaysia. \\ ${ }^{3}$ University Malaysia Pahang, Penang, Malaysia.
}

Accepted 3 August, 2011

\begin{abstract}
This study focuses on the satisfaction level of Small and Medium Enterprises (SMEs) with regards to the quality of non-audit services provided by Small and Medium Practitioners (SMPs) and their quality control practices. The objective is to examine the relationship between quality control, service quality and satisfaction and the mediating effect of the quality of SMPs' service on the relationship between quality control practices of SMPs and satisfaction level of SMEs. The results show that all the variables have partially significant relationship and there is mediating effect of service quality on the relationship between quality control and satisfaction. Relevant authority body should educate SMPs the importance of quality control and the way it can induce the quality of services provided and maximize client's satisfaction level without impairing their independent roles and compliance with standards, ethical, regulatory and legal requirements.
\end{abstract}

Key words: Quality control, service quality, satisfaction level.

\section{INTRODUCTION}

In this competitive world with ample choices of products and services, business organizations can retain their customers only if their customers are satisfied with their products and services. The benefits and importance of customer satisfaction have been widely acknowledged due to its substantial impact on customer royalty, and customer retention. Despite the importance of customer satisfaction, many business organizations fail to satisfy their customers due to many factors. Therefore, it is crucial to explore the factors that may solicit or impede customer satisfaction.

This study looks at the quality control practices and service quality of small and medium practitioners (SMPs) as possible factors of satisfaction of their clients that is

*Corresponding author. E-mail: hhasnah@usm.my. small and medium enterprises (SMEs) in the context of Malaysia. SMEs play a predominant role in the economy due to its presence in all sectors of the economy. Its importance has been highlighted due to its contribution to GDP, employment, as well as entrepreneur development. SMEs represent $99 \%$ of the commercial sector in Malaysia which contribute to $31 \%$ of the national economic growth (SME Annual Report, 2009)

Besides its benefits, SMEs in various sectors depend on each other as they supply their products and services to each other. Generally, SMEs lack resources and capabilities. Due to their lack of financial skills, they need to outsource for services such as accounting, and taxation services from SMPs, which are also small and medium sized. International Federation of Accountants (IFAC) has chosen to define SMPs as "accounting practices whose clients are mostly SMEs, external sources are used to supplement limited in-house technical 
resources, and contain a limited number of professional staff. What constitutes an SME differs depending on the country" (IFAC, 2010).

Based on the Malaysian Institute of Accountant (MIA)'s Annual Report 2010, there are a total of 2,036 firms that have registered with MIA and out of this total, 1,356 firms have been registered as an audit firm and another 680 firms were registered as non-audit firms. Based on the number of registered audit firms, $97 \%$ of these firms were categorised as SMPs and ninety percent of these SMPs are sole proprietors.

In Malaysia, SMPs provide both audit and non-audit services and most of their clients are SMEs. Non-audit services that SMPs provide include accounting, taxation, and regulatory requirements. Some SMPs have also extended their services into advisory and consulting to cater for business needs of the SMEs. In section 201 of the Sarbanes-Oxley Act 2002, it has been declared that firms are prohibited to take any specific non-audit service that may impair their professional independence (Sox, section 201: 772), however many SMPs still do so. This study focuses on the quality of non-audit services provided by SMPs to SMEs and satisfaction level of SMEs.

In terms of quality of the non audit services, SMPs seem to lose out compared to the Big 4 audit firms who have more resources and expertise. Section 111 of the Sarbanes - Oxley Act has ascertained that SMPs do not necessarily need to have an extensive accounting practice; procedures or code to conduct but it is necessary for them to have a good quality control on the quality of the services provided. Even though the SMP has audited and evaluated the SME, the barrier still could be the lack of quality in delivery services. This is because SMPs' quality control systems are usually not that strong, and they are often led by persons who lack in management and technical skills. Quality control of the SMPs is not as extensive as those of big firms, where the auditors cannot rely on the system to make their audits more efficient. Therefore, this study focuses on the satisfaction level of SMEs with regards to the quality of non-audit services (NAS) and quality control practices of SMPs.

\section{Non-audit services}

Non-audit services is defined as services rendered by the accounting firm that do not result in the expression of an opinion, negative assurance, a summary of findings or other form of assurance (Grill and Cosserat, 1996). Examples of the services are accounting, tax compilation, management consulting or advisory services and insolvency and business recovery. Audit firms are required to separate the non-audit service provided to the clients. They are not allowed to provide both services to the same client at the same time.

An interview with several small practitioners indicated that the non-audit services that they usually supply or offer to SMEs are the internal audit review, preparing accounts, setting up of an accounting system, advise to go for listing, applying for financing, applying for manufacturing license, preparing for customs declaration, preparing tax returns, tax planning and secretarial practices. These services can be broadly categorised into four areas: (1) secretarial practice, (2) consultation applying for financing, doing accounting work, (3) taxpreparing tax return and tax planning, (4) internal audit review. In Malaysia, the Malaysian Approved Standards on Auditing defined audit related services (ARS) as reviews, agreed-upon procedures and compilation.

Non-audit services and audit related services are different but may be provided by the same audit firms that audits the company. As providing ARS is part of the assurance service, auditors are not questioned by independence issue as the ARS provides lesser assurance than audit does (Arens et al., 1999). On the other hand, providing NAS have been associated with impairment of independence. Non-audit service has been a widely researched area. Many of previous studies examined the relationship of fees paid to non-audit services and fees paid to audit services, while others examined whether providing NAS would impair auditor independence as discussed earlier.

\section{Problem statement}

In exploring the opportunity to enhance the support provided by the SMPs to the SMEs, it is important to understand the business needs of the SMEs and identify areas where accountants in public practice could focus on in addition to the areas currently serviced. At the same time, the barriers preventing the SMPs in meeting the needs of the SMEs need to be understood.

One of the barriers could be the lack of quality in delivering its services. This is because SMEs' internal control systems are usually not that strong, and they are often led by persons who lack in management and technical skills. Internal controls of the SMEs are not as extensive as those of large companies, where auditors cannot rely on the system to make their audits more efficient. The lack of formal internal control systems and the application of universal auditing standards have given rise to the use of a special "small company audit qualification" in the UK (Keasey et al., 1988).

In Malaysia, although there is no decision made to date, nevertheless there is an inclination to give an "audit exemption" to SME. What it means is that SMEs should not be sub-jected to compulsory audit as there are too many weaknesses in control and would be difficult for auditors to issue an unqualified opinion. As a result, 
auditors would be placed in a difficult position as issuance of a qualified opinion would lead to a possibility that he will no longer be appointed as an auditor next year. In summary, audit of SME would be most likely to impair auditor's independence. For that matter even if the auditor was to give a qualified opinion, SMEs would not be able to rectify the matter due to lack of resources such as staff, fund and skill.

According to Sarbanes-Oxley Act of 2002 title II Section 201 point $G$ and $H$, registered public accounting firm may engage in any non-audit service, including tax services, only if the activity is approved in advance by the audit committee of the issuer. The Non-audit services are:

(1) Bookkeeping or other services related to the accounting records or financial statements of the audit client;

(2) Financial information systems design and implementation;

(3) Appraisal or valuation services, fairness opinions, or contribution-in-kind reports;

(4) Actuarial services;

(5) Internal audit outsourcing services;

(6) Management functions or human resources;

(7) Broker or dealer, investment adviser, or investment banking services;

(8) Legal services and expert services unrelated to the audit; and

(9) Any other service that the Board determines, by regulation, is impermissible.

According to Carcello et al. (2002) the firms that demands higher quality audit will be willing to pay a higher fees. As SMPs are small-medium sized films, the quality of audit can be low in term of control and delivery services. The independence of the SMPs can also be jeopardized. The MIA By-Law B1-6 has defined that the level of audit fees as any amount of fees charged to the client as long as it does not jeopardized auditor's professionalism. On the other hand, the level of fees depends on the quality control and quality of services delivered.

\section{Research questions}

Based on the problem statement, this study intends to answer the following research questions:

(1) Is there any relationship between quality control of SMPs and satisfaction level of SMEs with regards to nonaudit services?

(2) Is there any relationship between quality control of SMPs and quality service of SMPs with regards to nonaudit services provided to SMEs?

(3) Is there any relationship between quality service of SMPs and satisfaction level of SMEs with regards to non- audit services?

(4) Is there any mediating effect of quality service on the relationship between quality control and satisfaction level?

\section{LITERATURE REVIEW}

The theoretical framework of this study is based on quality theory.

\section{Quality theory}

De Angelo (1981) introduced the quality theory model as shown in Figure 1, where the control on the audit firm is divided into four factors: One controlling on the firm factors such as human resource, control process, and industry experience. The second factors refer to controlling on audit team factors such as supervision, planning, and performance the service, client experience and professionalism.

Furthermore, studies by DeAngelo (1981) and Palmrose (1986) suggests that detecting the material misstatements is influenced by how well the quality control system on the audit firm influence the audit team in performing their services. Simunic (1984) developed a model in which audit fees are cross-subsidised by nonaudit work: Competitive pressures in the audit market might then compel auditors to discount their audit fees, so that higher non-audit profits would be associated with lower audit fees. Simunic (1984) suggested that as an outcome to high service quality, auditor able to charge higher fees.

\section{Customer satisfaction}

Customer satisfaction and its antecedent and outcomes have been well-researched, especially in the marketing literature. Customer satisfaction or dissatisfaction results from experiencing a service and comparing that experience with the kind of quality of service that was expected (Oliver, 1980). Kotler (2000) defines satisfaction as "a person's feeling of pleasure or disappointment resulting from comparing a product's perceived performance (or outcome) in relation to his or her expectations".

According to Hansemark and Albinsson (2004), "satisfaction is an overall customer attitude towards a service provider, or an emotional reaction to the difference between what customers anticipate and what they receive, regarding the fulfilment of some need, goal or desire". Hoyer and MacInnis (2001) suggest that satisfaction can be associated with feelings of acceptance, happiness, relief, excitement, and delight. Crosby et al. 


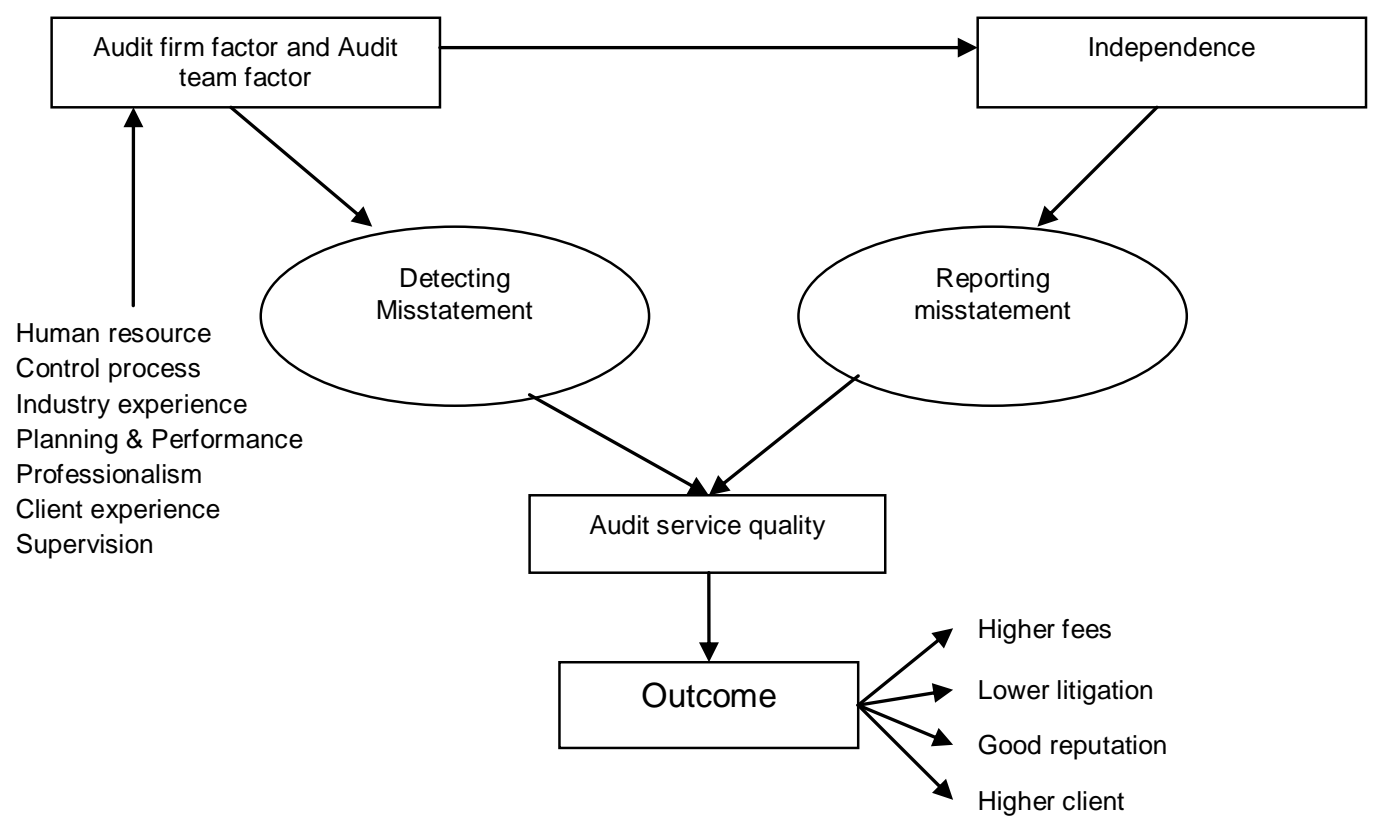

Figure 1. De Angelo audit quality model (De Angelo's report in journal of accounting and economic).

(1990) demonstrated that customer's past satisfaction affects their decisions to have a continuing relationship with the service provider. Similarly, Fornel (1992) found that a satisfied customer tends to maintain their consumption pattern and will consume similar products or services. Thus, customer satisfaction has become an important indicator of service quality and future revenue (Andreassen, 1994).

\section{Quality control}

A firm is required to establish a system of quality control designed to provide it with reasonable assurance that the firm and its personnel comply with professional standards and applicable regulatory and legal requirements. Quality control theory introduced by De Angelo (1981) states that audit firms should have a high quality control on the firm's activities and also on the audit teamwork. Wooten (2003) suggests that the quality control is influenced by many factors such as the firm size, human resource control, industry experience and the audit team.

The system of quality control encompasses its organizational structure and the policies adopted and procedures established to provide the firm with reasonable assurance of conforming to professional standard (statement on quality control standard no.10 point 3). This quality control is the guidance to ensure the firms follow the professional standards. The ISQC was introduced in 2005 as an approved Standard on Auditing in Malaysia. It was introduced by the Malaysian Institute of Accountants (MIA) to ensure a high degree of public confidence through the setting and maintaining a high professional standard among its 18,000 members audit firms.

The main reason for complying with ISQC is to establish basic principles, appropriate procedures and to provide guidance regarding firm's responsibilities in its audit system of quality control. In addition, it shall ensure high degree of confidence to the public on the quality of audit services. The system of quality control is required to include documented policies and procedures addressing:

(a) Leadership responsibilities.

(b) Ethical requirements.

(c) Accept and continuance of client relationships and specific engagements.

(d) Human resources.

(e) Engagement performance.

(f) Monitoring.

\section{Service quality}

Several studies have several definitions of service quality. Lewis and Booms (1983) defined service quality as a measure of how well the service level delivered matches customer expectations. Delivering quality service means conforming to customers' expectations on a consistent basis. However, Parasuraman et al. (1985) argue that most researchers and managers of service firms agree that service quality involves a comparison of 
expectations with performance.

Gronroos (1984) proposes that there are two types of service quality, technical and functional quality. Technical quality involves what the customer is actually receiving from the service. The customer can often measure the service outcome in an objective manner. Functional quality is the manner in which the service is delivered which refers to the interaction between service provider and recipient of a service. The conceptual model of service quality developed by Gronroos (1984) is the first one which the purpose is to increase understanding of customers' service quality perceptions and the factors that influence those perceptions.

Parasuraman et al. (1985) developed another model for service quality known as SERVQUAL. This model provides a technology for measuring and managing service quality which attempts to prove the salient activities of the service organization that influence the perception of quality. Ziethaml et al. (1990) defines service quality as a multidimensional concept and they identified there are five key dimensions of service quality. The first concept is reliability. Reliability is defined as the ability to deliver the promised service dependably and accurately. It is a situation when keeping promises of delivery, price and complaint handling. Secondly, responsiveness is described as willingness to help customers and provide prompt service. It measures stresses service personnel's attitude to be attentive to customer requests questions and complaints. Thirdly, assurance is the service quality dimension that focuses on the ability to inspire trust and confidence. Fourthly, empathy is the service aspect that stresses the treatment of customers as individuals. Lastly, tangibles are the service dimension that focuses on the elements that represent the service physically. This study uses six dimensions of service quality with additional dimension: knowledgeable. This dimension was generated by research team to suit the context. Knowledgeable represents the level of knowledge with SMP as part and parcel of their service quality.

A study by Ismail et al. (2006), which used SERVQUAL model in auditing sector, found that public listed companies in Malaysia were only satisfied with tangible dimensions and customer loyalty partially mediated the relationship between reliability and customer satisfaction. Bungsu (2004) states that there is a positive relationship between customer loyalty and service quality but he found that SMEs were not satisfied with all the SERVQUAL dimensions especially on reliability dimensions. Che Din (2008) used partial SERVQUAL model to examine the relationship between SMEs perceptions on service quality and level of fees.

\section{Theoretical framework}

Based on the literature and quality theory, this study proposes a theoretical framework that holds satisfaction level as dependent variable, quality control as independent variable and quality service as mediating variable. According to the framework, quality of service mediates the relationship between quality control and customer's satisfaction. It posits that in order to achieve clients' (SMEs) satisfaction, SMPs must improve their quality of service by tightening the quality control practices (Figure 2).

\section{HYPOTHESIS DEVELOPMENT}

Based on framework, following hypotheses were developed between three variables.

\section{Quality control and satisfaction}

Customer satisfied with the services, meaning any level of price charged by the auditor will not be arguable by their customer (Engel et al., 2007). Forza and Filippini (1998) addressed that in total quality management, it is essential to improve the quality control regarding the customer satisfaction. Company has to maintain the relationship with the customers by satisfying them (Forza and Filippini, 1998). Dean and Bowen (1994) argued that manufacturers have to attach the customers in product designed in term of satisfying the customer. ISQC also mentioned that quality control has to be maintained by audit firm not only for auditor independency, but also for client's satisfaction. Therefore, the study hypothesizes as follow:

$\mathbf{H}_{1}$ : The higher the quality control of SMPs, the higher the satisfaction level of SMEs.

\section{Quality control and service quality}

Many studies have proven that the success of quality control was driven by high service quality (DeAngelo, 1981; Ridley, 1994; Bij and Ekert, 1999). Low control on production process or service will cause low service quality which means the detection of misstatement or product defect increased (Lian, 2001). Lian (2001) also states that the success of service quality and its impact is largely within the control of leadership. According to Ridley (1994), quality control and quality service interact with each other. The success of service quality was driven by the high quality control on product or services. Based on the literature, this study posits following hypothesis.

$\mathbf{H}_{2}$ : The higher the quality control of SMPs, the higher the quality services of SMPs. 


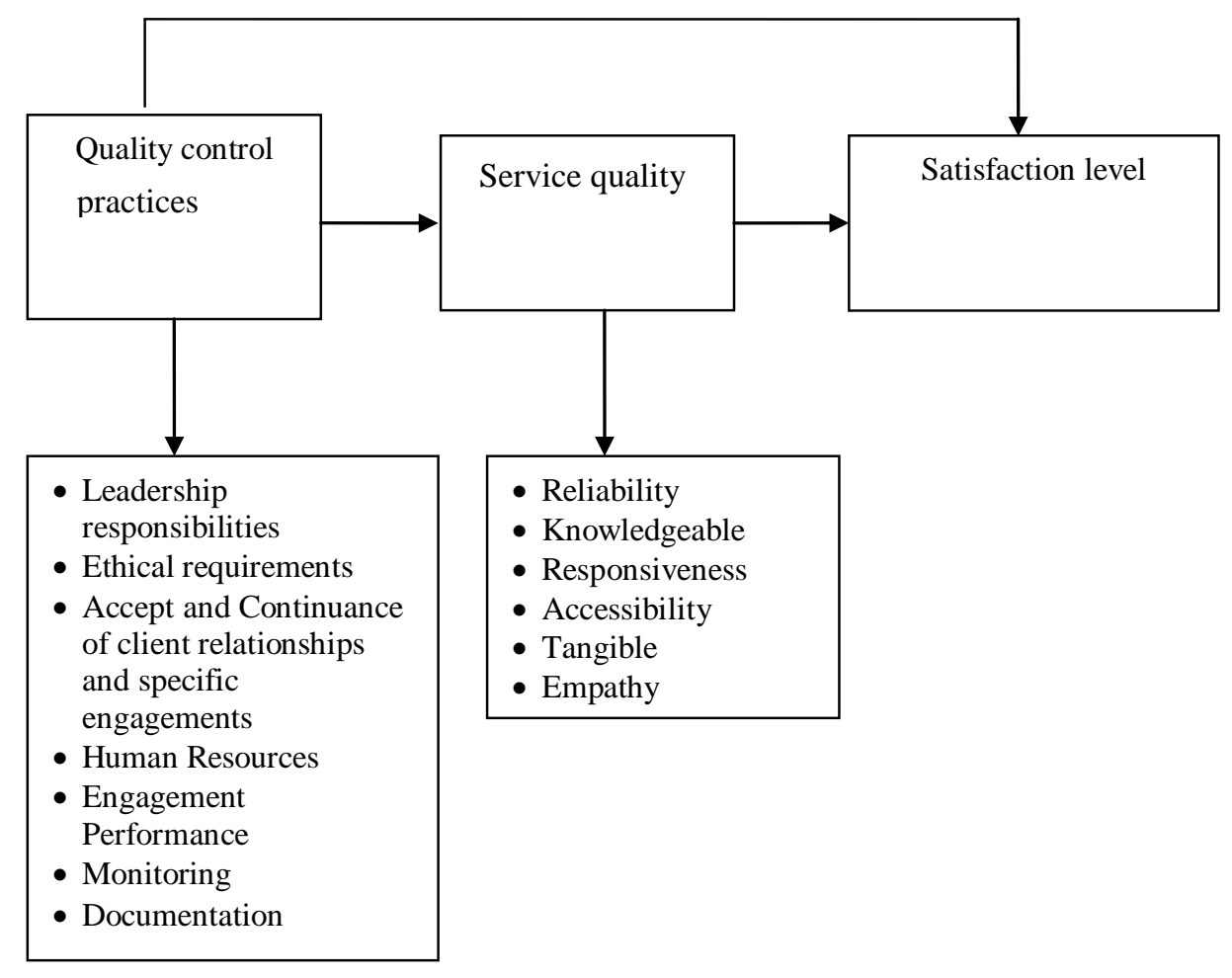

Figure 2. Theoretical framework.

\section{Service quality and satisfaction}

Fornell et al. (1996) state that, customer satisfaction is actually a perception of quality which means satisfaction of customer depends on the way customer value the quality delivery. It is supported by Cronin et al. (2000), who address that there is a relationship between quality of delivery and satisfaction. The authors propose the behavioural intention as the background theory that can help scholar to prove the relationship. In other words, it can be surmised that the higher is the service quality, the higher is the satisfaction. Therefore, the study hypothesizes as follow:

$\mathbf{H}_{3}$ : The higher the service quality of SMPs, the higher the satisfaction level of SMEs.

The mediating effect of service quality on the relationship between quality control and satisfaction level

As mentioned earlier, many studies (DeAngelo, 1981; Ridley, 1994; Bij and Ekert, 1999) have proven the relationship between quality control and quality of service. According to Ridley (1994), quality control and quality service interact with each other. The success of service quality can also drive the customer satisfaction. Fornell et al. (1996) state that satisfaction of customer depends on the way customer values the quality of service. Meanwhile, quality control relationship to satisfaction has also investigated by scholars such as Engel et al. (2007). Ismail et al. (2006) argues that optimum quality control in audit firm can maximize the client's satisfaction. It implies that there can be mediating effect of quality of delivery on the relationship between quality control and satisfaction level. Therefore, this study hypothesizes that:

$\mathbf{H}_{4}$ : The service quality mediates the relationship between quality control of SMPs and satisfaction level of SMEs.

\section{METHODOLOGY}

Due to the absence of information and limited studies on quality of non-audit service, this study is designed to be exploratory in nature. Unit of analysis used in this study is dyad between two respondents: SMEs and SMPs. Dyad means pairs are identified as 1 unit of analysis. The population of SMEs for this study is those listed in the SMEs Business Directory for the year 2007. Targeted sample size is 200 pairs. Targeted respondent for SMEs is the staff at top management level for SMEs, and for SMP, the staff at senior level and above who provides non-audit service.

Since this study uses dyad method, there were 2 sets of survey questionnaires meant for two respondents: One for SMEs and the other for SMPs. The one for SMEs includes three sessions: 
Company profile, service quality, and satisfaction level. The one for SMPs includes two sessions: Company profile, and quality control.

1000 questionnaires were distributed by means of both mailing and personal visits to collect the questionnaires from respondents. Despite using a few different way of data collection, the response rate was too low and, a total of 53 pairs of questionnaires were collected and used for analysis. The possible reason of low response rate is that many SMPs concern that the findings of the study would have negative impact on the regulation imposed on them.

\section{Measurements}

Quality control: Questionnaire items of quality control were originally built by holding discussions and standards requirement in practice review. Measurements were based on International standard quality control (ISQC), which is regulation audit firms are required to comply with. Respondents were asked to rate the scale of 1 (strongly disagree) to 5 (strongly agree) for a total of 49 items, which covers 7 dimensions (leadership responsibilities, ethical requirements, accept and continuance of client relationships and specific engagements, human resources, engagement performance, monitoring, documentation).

Service quality: Questionnaire items of service quality were adapted from Ismail et al. (2006). Respondents were asked to rate the scale of 1 (strongly disagree) to 5 (strongly agree) for a total of 18 items, which covers 6 dimensions (tangible, knowledgeable, responsiveness, reliability, empathy, accessibility).

Satisfaction: Questionnaire items of satisfaction were built by holding discussions. Respondents were asked to rate the scale of 1 (strongly disagree) to 5 (strongly agree) for a total of 4 items.

\section{FINDINGS}

Table 1 gives a glance of demographic profile of SMEs respondents. Most of the SMEs are in manufacturing, services and other type of industries. Majority are small sized with number of employees 5 to 19 . Annual sales turnover ranges from $\mathrm{RM} 200,000$ to more than $\mathrm{RM}$ $10,000,000$

\section{Non-audit services provided by SMPs to SMEs}

It was found that the most of common type of NAS provided by SMPs to SMEs are tax returns, secretarial practice, tax planning, and preparation of full set of account (Table 2).

\section{Relationship between quality control and satisfaction level (RQ1)}

To test Hypothesis 1, multiple regressions were run to determine the relationship between quality control and satisfaction level. As per Table 3, the model is significant $(F=27.784 ; p<0.001)$. The model explains $81.9 \%$ of the variation in satisfaction level of SMEs on quality control of SMPs. Level of satisfaction have significant positive relationship with two dimensions of quality control dimensions such as human resource $(\beta=0.629 ; p<0.001)$ and documentation $(\beta=0.193 ; p<0.05)$. Therefore, the results support the hypothesis that quality control dimensions (that is human resource and documentation) positively influence the satisfaction.

\section{Quality control and service quality (RQ2)}

To test hypothesis 2, multiple regression was run to determine the relationship between quality control and quality service. Table 4 depicts the result of regression between quality control and service quality. Certain dimensions of quality control were found to have significant relationship with service quality dimensions. Tangible has significant relationship with acceptance and continuance $(\beta=0.315 ; \quad p<0.05)$ and documentation $(\beta=0.397 ; \quad p<0.001)$. Knowledgeable has significant relationship with acceptance and continuance $(\beta=0.329$; $p<0.01)$ and human resources $(\beta=0.793 ; p<0.001)$. Responsiveness has significant relationship with ethical requirements $(\beta=0.777 ; p<0.001)$ and acceptance and continuance $(\beta=0.270 ; p<0.05)$. Reliability has significant relationship with ethical requirements $(\beta=0.550$; $p<0.001)$. Accessibility has significant relationship with leadership responsibilities $(\beta=0.777 ; \quad p<0.001)$ and Monitoring $(\beta=0.545 ; \quad p<0.01)$. Lastly, empathy has significant relationship with acceptance and continuance $(\beta=0.714 ; p<0.001)$.

\section{Service Quality and satisfaction level (RQ3)}

The regression results of service quality and satisfaction level indicate that there is a significant relationship between the service quality and level of satisfaction. The $F$ value of 46.066 is significant $(p<0.001)$, indicating that there is at least one significant predictor. $R^{2}$ of 0.874 indicates that the model explains $87.4 \%$ of the variance in satisfaction (explained by the independent variables). Two of the dimensions of service quality are found to have significant relationship with satisfaction level. Knowledgeable $(\beta=0.713 ; p<0.001)$ and accessibility $(\beta=0.244$; $p<0.05$ ) are positively related to satisfaction level (Table $5)$.

The mediating effect of service quality on the relationship between quality control and satisfaction level (RQ4)

A hierarchical regression with four models was used to examine if there was any mediating effects of service quality on the relationship between quality control and satisfaction level. A variable may be considered as a 
Table 1. SMEs' profile.

\begin{tabular}{llc}
\hline & & Percentage (\%) \\
\hline \multirow{4}{*}{ Type of industry } & Manufacturing & 28.3 \\
& Manufacturing-related service & 1.9 \\
& Services & 26.4 \\
& Trading & 43.4 \\
& & \\
& Less than 5 & 28.3 \\
Full time employee & $5-19$ & 45.3 \\
(number) & $20-50$ & 13.2 \\
& $51-100$ & 5.7 \\
& More than 100 & 7.5 \\
Annual sales turn & & \\
over & RM 200000 - RM 1000000 & 24.5 \\
& RM1001000 - RM 5000000 & 30.2 \\
& RM 5000000 - RM 10000000 & 20.8 \\
& More than RM 10000000 & 15.1 \\
\hline
\end{tabular}

Table 2. The type of non-audit services SMEs are getting from SMPs.

\begin{tabular}{lc}
\hline Type of non-audit services & Percentage (\%) \\
\hline Tax returns & 83 \\
Secretarial practice & 60.4 \\
Tax Planning & 52.8 \\
Full set of account & 45.3 \\
Computerized accounting system & 17 \\
Applying for loan & 13.2 \\
Working paper for clients & 13.2 \\
Asset Valuation & 9.4 \\
Internal audit & 9.4 \\
Applying for manufacture license & 7.5 \\
Business development & 7.5 \\
Improve business performance & 5.7 \\
Accounting training to clients & 3.8 \\
Fund/Asset Management & 3.8 \\
Prepare customs declaration & 1.9 \\
\hline
\end{tabular}

mediator (MV) to the extent it carries the influence of a given independent variable (IV) to a given dependent variable (DV). According to McKinnon et al. (1995), mediation is generally present when:

(a) The IV significantly affects the mediator,

(b) The IV significantly affects the DV in the absence of the mediator,

(c) The mediator has a significant unique effects on the DV, and

(d) The effect of the IV on the DV shrinks upon the
Table 3. Relationship between quality control and satisfaction.

\begin{tabular}{lc}
\hline Quality control & Satisfaction $(\boldsymbol{\beta})$ \\
\hline Leadership responsibilities & 0.090 \\
Ethical requirement & -0.111 \\
Acceptance and continuance & 0.088 \\
Human resources & $0.629^{\star \star \star}$ \\
Engagement performance & 0.321 \\
Monitoring & -0.200 \\
Documentation & $0.193^{\star}$ \\
$\mathrm{R}^{2}$ & 0.819 \\
Adjusted $\mathrm{R}^{2}$ & 0.789 \\
$\mathrm{~F}$ & $27.784^{\star \star *}$ \\
\hline
\end{tabular}

addition of the mediator to the model.

It was found that the result of the regression met all conditions above.

The model 1 was run with quality control (IV) and service quality (MV). The model 2 model was run with quality control (IV) and satisfaction level (DV). The model 3 was run with knowledgeable dimension of service quality (IV) and satisfaction level (DV). The model 4 was run with quality control (IV), knowledgeable and satisfaction Level (DV). The result shows that the knowledgeable dimension of service quality has mediating effect on the relationship between human resources dimension of quality control and satisfaction (Table 6). 
Table 4. Relationship between quality control and service quality

\begin{tabular}{|c|c|c|c|c|c|c|}
\hline \multirow[b]{2}{*}{ Quality control dimensions } & \multicolumn{6}{|c|}{ Service Quality dimensions } \\
\hline & $\begin{array}{c}\text { Tangible } \\
(\beta)\end{array}$ & $\begin{array}{c}\text { Knowledgeable } \\
(\beta)\end{array}$ & $\begin{array}{c}\text { Responsiveness } \\
(\beta)\end{array}$ & $\begin{array}{c}\text { Reliability } \\
(\beta)\end{array}$ & $\begin{array}{c}\text { Accessibility } \\
(\beta)\end{array}$ & $\begin{array}{c}\text { Empathy } \\
(\beta)\end{array}$ \\
\hline Leadership responsibilities & & & & & $0.667^{* * *}$ & \\
\hline Ethical Requirements & & & $0.777^{\star \star \star}$ & $0.550^{\star *}$ & & \\
\hline Acceptance and continuance & $0.315^{\star}$ & $0.329^{\star \star}$ & $0.270^{*}$ & & & $0.714^{\star \star \star}$ \\
\hline Human resources & & $0.793^{* * *}$ & & & & \\
\hline \multicolumn{7}{|l|}{ Engagement performance } \\
\hline Monitoring & & & & & $0.545^{\star *}$ & \\
\hline Documentation & $0.397^{* * *}$ & & & & & \\
\hline
\end{tabular}

${ }^{*} p<0.05,{ }^{* *} p<0.01,{ }^{* * *} p<0.001$.

Table 5. Relationship between services quality and satisfaction.

\begin{tabular}{lc}
\hline Services Quality & Satisfaction $(\boldsymbol{\beta})$ \\
\hline Tangible & 0.090 \\
Knowledgeable & $0.713^{\star \star \star}$ \\
Responsiveness & -0.097 \\
Reliability & 0.128 \\
Empathy & -0.041 \\
Accessibility & $0.244^{\star}$ \\
R $^{2}$ & 0.874 \\
Adjusted $R^{2}$ & 0.855 \\
F & $46.066^{\star \star \star}$ \\
\hline
\end{tabular}

${ }^{*} \mathrm{p}<0.05,{ }^{* *} \mathrm{p}<0.01,{ }^{* * *} \mathrm{p}<0.001$

\section{DISCUSSION}

This research aims to investigate the relationship between quality control, service quality, and satisfaction level. Concerning the first research question, results indicates a significant relationship between two dimensions of quality control (human resource and documentation) and satisfaction. Human resource in quality control means the SMP staffs have capabilities, competencies, and authorities to perform their non-audit service. The staffs have to deliver these services to make SMEs satisfy with the non-audit services. In other words, the skill and technical ability in performing non-audit can enhance the satisfaction of SMEs. This finding is in line with Cronin and Taylor (1992). The authors suggest that quality control is the determinant of client's satisfaction by showing the capabilities of audit firm solving client's problems. It implies that establishing the culture, reward and punishment, training, and other engagement that related to quality control has important role to satisfaction level of customers. The human resource leads the employee to be more aware to quality which results to joy and pleasure of the customers.

Concerning the second research question, the study found that there is a significant relationship between several dimensions of quality control and the service quality. As the study can see from the Table 4 , certain dimension of quality control has relationship with certain dimension of service quality. As per Table 4, the first dimension of quality control, leadership has significant relationship with the accessibility of quality service. The responsibility of SMPs as a leader such as establishes policies and procedures, quality control performance responsibility, and compensation on performance, assessment, and appraisal can induce the accessibility of service quality. It implies that the responsibility of SMPs as leader can give proper engagement work or clear and understandable non-assurance service report. This is consistent with Lian (2001), who states that the success of service quality is from the control of leadership.

Ethical requirement is related to responsiveness and reliability. The ethical requirement is important when providing the service. This is to show that help the auditor to control themselves to be more independent in their work performed. This result implies that SMPs should maintain the code of ethics and independent in providing non-audit service to enhance the service quality. From the hypothesis, the study can conclude that although SMPs understand their client's need, they still manage to control themselves to be independent and not controlled by their client when providing the service. It was also found that the acceptance and continuance dimension in quality control has significant relationship with the tangible, knowledgeable, responsiveness and empathy. It implies that if SMPs can employ assessment criteria on client's reputation and internal control environment, or can identify clients' principal owners, key management, related parties and those charged with its governance, the perceived of quality service in SMEs will be higher in term of tangible, knowledgeable, responsiveness 
Table 6. Mediating effect of service quality on the relationship between quality control and satisfaction.

\begin{tabular}{|c|c|c|c|c|c|c|c|c|}
\hline \multirow[b]{2}{*}{ Predictor } & \multicolumn{2}{|c|}{ Model 1} & \multicolumn{2}{|c|}{ Model 2} & \multicolumn{2}{|c|}{ Model 3} & \multicolumn{2}{|c|}{ Model 4} \\
\hline & $\begin{array}{c}\text { Standardized } \\
\text { coefficients } \\
\beta\end{array}$ & $\mathbf{T}$ & $\begin{array}{c}\text { Standardized } \\
\text { coefficients } \\
\beta\end{array}$ & $\mathbf{T}$ & $\begin{array}{c}\text { Standardized } \\
\text { coefficients } \\
\beta\end{array}$ & $\mathbf{t}$ & $\begin{array}{c}\text { Standardized } \\
\text { coefficients } \\
\beta\end{array}$ & $\mathbf{t}$ \\
\hline Constant & & -0.508 & & -0.941 & & & & \\
\hline Leadership Responsibilities & 0.059 & 0.460 & 0.090 & 0.737 & & & 0.188 & -0.419 \\
\hline Ethical Requirement & -0.134 & -0.970 & -0.111 & -0.842 & & & -0.051 & 1.994 \\
\hline Acceptance and Continuance & $0.329^{\star *}$ & 2.759 & 0.088 & 0.775 & & & -0.162 & -0.517 \\
\hline Human Resources & $0.793^{\star * \star}$ & 5.667 & $0.629^{\star \star \star}$ & 4.720 & & & $0.259^{*}$ & -1.647 \\
\hline Engagement Performance & -0.024 & -0.113 & 0.321 & 1.564 & & & $0.366^{*}$ & 2.039 \\
\hline Monitoring & -0.158 & -0.645 & -0.200 & -0.855 & & & -0.170 & 2.362 \\
\hline Documentation & 0.057 & 0.615 & $0.193^{*}$ & 2.171 & & & 0.017 & -0.977 \\
\hline Knowledgeable & & & & & $0.851^{* * *}$ & 11.346 & $0.599^{* \star *}$ & 0.248 \\
\hline $\mathrm{F}$ & \multicolumn{2}{|c|}{$24.767^{\star \star \star}$} & \multicolumn{2}{|c|}{$27.784^{* * *}$} & \multicolumn{2}{|c|}{$128.734^{\star * *}$} & \multicolumn{2}{|c|}{$51.763^{\star \star \star}$} \\
\hline $\mathrm{R}^{2}$ & \multicolumn{2}{|c|}{0.801} & \multicolumn{2}{|c|}{0.819} & \multicolumn{2}{|c|}{0.724} & \multicolumn{2}{|c|}{0.916} \\
\hline Adjusted $\mathrm{R}^{2}$ & \multicolumn{2}{|c|}{0.769} & \multicolumn{2}{|c|}{0.789} & \multirow{2}{*}{\multicolumn{2}{|c|}{$\begin{array}{c}0.719 \\
128734\end{array}$}} & \multicolumn{2}{|c|}{0.898} \\
\hline F Change & \multicolumn{2}{|c|}{24.603} & \multicolumn{2}{|c|}{27.784} & & & \multicolumn{2}{|c|}{51.763} \\
\hline
\end{tabular}

${ }^{*} \mathrm{p}<0.05,{ }^{* *} \mathrm{p}<0.01,{ }^{* * *} \mathrm{p}<0.001$.

and empathy. The acceptance and continuance of quality control can induce the feeling and emotion of SMEs.

The results indicate that human resource also has significant relationship with the knowledgeable dimension. It implies the quality control in staff capabilities, competencies, and authorities plays important role on the knowledgeable dimension in service quality. The service that is delivered has to consist of current information and knowledge. To deliver this type of service, indeed SMPs has to have competent and capable Staff. This finding is in line with Che Din (2008). Besides that, monitoring dimension in quality control has significant relationship with the accessibility dimension of service quality. It indicated that
SMPs must establishes policies and procedures to ensures the services are being carried out properly, efficiently and not exposing the firm to claim and litigation and compliance with standards, ethical, regulatory and legal requirements. With the good monitoring process can directly the firm documents the engagement work properly and the report on the services performed is clear and understand. This findings is similar with Che Din (2008).

Lastly, there is relationship between documenttation in quality control and tangibility in service quality. It implies that appropriate documentation can enhance the tangibility of service quality. The appropriate documentation in the internal contro system will bring a good planned and prepared non-audit works and reports. Therefore, it will increase the service quality of the non-audit service. Referring to the third research question on the relationship between service quality and satisfaction level, the result shows that only two dimensions of service quality (knowledgeable and accessibility) have significant relationship with satisfaction. It implies that knowledge ability and accessibility of SMPs' service can induce the SMEs' satisfaction. Parasuraman et al. (1991) addresses that reliability was ranked as the most important, followed by assurance dimension, with the least important being the dimension tangibles in service firms. This is different with the research result. This research suggests knowledgeable as the most significant factors in service quality. 
The high significance of knowledgeable dimension suggests that SMEs do not expect SMPs to perform the service independently and accurately in the best form. SMEs are more concerned about the knowledge aspect of services to enhance the satisfaction level of its clients. It means the quality delivery process has to be a learning process for the clients. As depicted by the result, the clients will have higher satisfaction level, if the quality delivery has higher knowledgeable contained. This finding confirms Ting (2004), who finds that SMEs need to response to new threat as their response can reduce the high risk of being wipe out from the business. On the other hand, the findings contradict with that of Ismail et al. (2006). The authors found that listed companies in Malaysia expect audit firms to perform the services accurately. In other words, big companies are more concern to the reliability and assurance dimensions. Big companies give less concern into the tangible. To big companies, the appearance of audit firm's physical infrastructure is not as important when delivering the audit task as they already used and equipped with the latest technology (Ismail et al., 2006). Therefore, the tangible dimension will not affect the satisfaction of big company.

Referring to the fourth research question on the mediating effect of service quality on the relationship between quality control and satisfaction level, the result shows that there is mediating effect of service quality on the relationship between quality control and satisfaction level. It means that the knowledgeable quality service bridge the human resource quality control to satisfaction. SMPs have to enhance their human resources part to give high satisfaction to SMEs. Additionally, SMPs have to ensure their human resource has the neccessary knowledge to deliver quality services to SMEs so that high satisfaction by clients is achieved.

\section{IMPLICATIONS AND CONCLUSION}

This research offers interesting findings regarding the relationship between quality control, service quality, and satisfaction. The study found that there is significant relationship between several dimensions in quality control and the service quality. The study also found the significant relationship between quality control and satisfaction, and between service quality and satisfaction. The findings imply that SMPs' quality control can induce the quality services. In auditing context, according to Generally Accepted Accounting Standard and Code of Professional Conduct, one of the acts mentions vividly that auditors are not allowed having interest in any circumstance (including the quality control) to its clients. It is made to maintain SMPs independency and integrity without any influences. Auditing practice monitoring body such as MIA, IASB, and ASB do not want audit firm to lose their quality control just to satisfy the clients. This is in line with finding of Ismail et al. (2006) which states that audit firms must continuously strive to exceed client expectations and maximize client satisfaction by maintaining the quality control.

Based on the findings, enhancing the quality control will result in enhancing the service quality and clients' satisfaction as there is significant relationship. It means SMPs should not lose their quality control as it will be contra productive strategy for them.

The findings in this part also relates to internal control. Messier (2000) addresses that the effectiveness of quality control is a function of the integrity value of the individuals who creates, administer, and monitor the controls. Our findings show that ethical requirement, acceptance and continuance, and leadership have significant relationship to several dimensions in quality service and also satisfaction. Thus, it confirms the findings of Messier (2000) who suggests that the integrity value plays role in quality control. In other words, it gives highlight in the auditing quality control by showing better quality control will be achieve in these three personal value in quality control dimensions (ethical requirement, acceptance and continuance, and leadership). Furthermore, in practice, if SMPs emphasize on the integrity value of their employee, SMPs will achieve better service quality and clients' satisfaction.

This study prompts two implications. Firstly, SMPs should stress on their quality control (especially Human resource) as it will induce client's satisfaction. It also offers suggestion to regulatory body such as MIA, IASB, $I A B$, or IAI, to inform the audit firms (especially SMPs) that improving the quality control will result in better client's satisfaction.

Theoretically, Parasuraman et al. (1990) addresses that service quality have significant relationship with satisfaction. In Malaysia's context, Ismail et al. (2006) found that service quality of audit firm have significant relationship to client's satisfaction. This study however found that service quality has partial significant relationship to satisfaction. Therefore, the study concludes that to provide quality service, SMPs must give attention to the knowledgeable attribute of the service quality. This study also delivers new perspective where SMPs should also give attention on the quality of the service provided as it can induce the client's satisfaction. For regulatory body, this research call for SMPs' attention to emphasize on their quality control as it can induce the level of service quality and increase client's satisfaction level.

\section{REFERENCES}

Andreassen TW (1994). "Satisfaction, loyalty and reputation as indicators of customer orientation in the public sector", Int. J. Pub. Sector Manag. 7(2):16-34. 
Anonymous (Sarbanes-Oxley Act) (2002). United State of America Congress.

Arens AA, Loebbecke JK, Iskandar TM, Susela SD, Isa S (1999). Auditing in Malaysia: An Integrated Approach. Malaysia: Prentice Hall (M) Sdn. Bhd.

Bij H, Ekert JHW (1999). Interaction between production control and quality control. Int. J. Oper. Prod. Manag. 19(7):674-690.

Bungsu H (2004). Quality of service and its relationship with customer loyalty : perceptions of audit client. MBA thesis, Sch. Manage., University Science Malaysia, Penang.

Carcello JV, Hermanson DR, Neal TL, Riley RA (2002). "Board characteristics and audit fees", Contemp. Acc. Res. 19(3):365-84.

Che Din D (2008). Quality control of service provider on non audit service, and the level of non audit fess: The perceptions of SMEs in Malaysia. MBA thesis, School of Management, University Science Malaysia, Penang.

Cronin JJ, Brady MK, Hult GTM (2000). Assessing the effects of quality, value and customer satisfaction on consumer behavioral intentions in service environments. J. Retailing 76(2):193-218.

Cronin JJ, Taylor SA (1992). Measuring service quality: a reexamination and extension. J. Mark. 56(7):55-68.

Crosby LA, Evans K, Cowles D (1990). "Relationship quality in services selling: an interpersonal influence perspective", J. Mark. 54:68-81.

Dean JW, Bowen DE (1994). "Management theory and total quality: improving research and practice through theory development", Acad. Manage. Rev. 19(3): 392-418.

DeAngelo L (1981). Auditor size and audit quality. J. Acc. Econ. 3:183199.

Engel E, Hayes RM, Wang X (2007). Audit committee compensation and demand for monitoring of the financial reporting process. University of Chicago.

Fornel C (1992). "A national customer satisfaction barometer: the Swedish experience", J. Mark. 56(1):1-2.

Fornell C, Johnson MD, Anderson EW, Cha J, Bryang BE (1996). The American customer satisfaction index: Nature, purpose, and findings. J. Mark. 60:7-18.

Forza C, Filippini R (1998). "TQM impact on quality conformance and customer satisfaction: a causal model", Int. J. Prod. Econ. 55(1):1-20.

Grill GS, Cosserat GW (1996). Modern Auditing in Australia (4 ${ }^{\text {th }}$ edition). Australia: Jacaranda Wiley Ltd.

Gronroos C (1984). A service quality model and its market implications. European J. Mark. 18(4):36-44.

Hansemark OC, Albinson M (2004). Customer Satisfaction and Retention: The Experiences of Individual Employees. Managing Serv. Qual. 14(1):40-57.

Hoyer WD, Maclnnis DJ (2001). Consumer Behaviour. 2nd ed., Boston, Houghton Mifflin Company.

IFAC (2010). The Role of Small and Medium Practices in Providing Business Support to Small and Medium sized Enterprises. International Federation of Accountants.
Ismail I, Haron H, Ibrahim DN, Isa SM (2006). Service quality, client satisfaction and loyalty towards audit firms: Perceptions of Malaysian public listed companies. School of Management, Universiti Sains Malaysia.

Keasey K, Watson R, Wynarczyk P (1988). "The small company audit qualification: a preliminary investigation", Acc. Bus. Res. 18(72):323333.

Kotler P (2000). Marketing Management. 10 $0^{\text {th }}$ ed., New Jersey, Prentice-Hall.

Lewis RC, Booms BH (1983). The marketing aspects of service quality. Emerging Perspective Service. Mark. pp.99-107.

Lian TKF (2001), Determinants of total quality management (TQM) implementation and impact: A study of selected Malaysian Public Organizations. (Doctoral dissertation, University of Georgia, USA, 2001.

McKinnon DP, Warsi G, Dwyer JH (1995). A simulation study of mediated effect measures. Multivariate Behavioral Res. 30(1):41-62.

Messier W (2000). Auditing and Assurance Services: A Systematic Approach. 2nd Revised ed. McGraw-Hill Inc., US.

Oliver RL (1980). A Cognitive model of the antecedents and consequences of satisfaction decisions. J. Mark. Res. 17(11):460 469.

Palmrose Z (1986). Audit fees and auditor size: further evidence. J. Acc. Res. 24(1):97-110.

Parasuraman A, Berry LL, Zeithml VA (1990). An empirical examination of relationships in extended service quality model. MSI Report, Cambridge: Mark. Sci. Instit. pp.90-122.

Parasuraman A, Berry LL, Zeithml VA (1991). Refinement and reassessment of the SERVQUAL scale. J. Retailing 67(4):420-450.

Parasuraman A, Zeithaml VA, Berry LA (1985). "A conceptual model of service quality and its implications for future research", J. Mark. 49:41-50.

Ridley J (1994). Does Quality Control Services? TQM Mag. 6(6):17-18.

Simunic D (1984). Auditing, consulting and auditor independence. J. Acc. Res. (Autumn) pp.679-702.

SME Annual Report (2009). Transformation to the New Economic Model. National SME Development Council.

Ting OK (2004). "SMEs in Malaysia: pivotal points for Change", on line and available at http://www.mca.org.my.

Wooten TC (2003). Research about Audit Quality. The CPA J. 73(1):4851.

Zeithaml VA, Parasuraman A, Berry LL (1990). Delivering quality service: Balancing customer perceptions and expectations. New York: Free Press. 